\title{
Quem me tornei em meio à Filosofia?'
}

\section{Who did I become in the midst of Philosophy?}

JOSÉ ATÍLIO PIRES DA SILVEIRA²

\section{Boa noite!}

Agradeço a todos os presentes pela atenção e interesse em ouvir o que temos a dizer sobre os efeitos da Filosofia nas nossas vidas.

Gostaria de agradecer, também, aos organizadores dessa atividade pela oportunidade que nos dá para tratarmos sobre um tema tão íntimo e pessoal quanto o proposto para este momento. A produção de uma reflexão como essa nos obriga a lançar um olhar para o passado em busca das influências sobre o agora que nos lança e arremete para o amanhã possível.

Embora esta reflexão tenha como ponto de partida uma singularidade, isso não retira a possibilidade de lhe darmos um tratamento filosófico. Podemos problematizar a respeito da modulação com que a temática nos foi proposta, podemos afirmar que a escolha da formulação da pergunta se posiciona filosoficamente ao sugerir que somos livres e indeterminados o suficiente para nos tornarmos aquilo que resultamos ser. Podemos nos perguntar, também, se nos tornamos ou somos tornados?

A pergunta "Quem me tornei?" pode ser substituída pela que pergunta por "Quem me tornou?" ou, pela pergunta pelo "O que me tornou?" assim como sou.

Tenho preferência pela terceira formulação. Enquanto a primeira sugere que o tornar-se é algo que se deve, em última instância, àquilo que se torna; a segunda sugere o oposto, o tornar-se é algo que se deve a um agente externo. A terceira formulação nos permite compreender que somos tão determinados por nós mesmos quanto por fatores que nos são alheios.

Temos razões para acreditar que ambas as situações se desenvolvem concomitantemente. Ora somos pilotos que traçam rotas existenciais empregando como bússola nossa vontade e curiosidade, ora somos naus que singram os mares empurrados pelo fluxo das correntes que se impõem sobre nossos sonhos e desejos.

Umas das perguntas filosóficas mais difíceis de tratar é a que nos impele a saber “Quem somos?". Uma das razões da dificuldade em respondê-la está no fato de que ela faz com que nos tornemos objetos de nossa própria investigação e, nessa condição, não temos como cumprir uma exigência epistêmica que garantiria rigor e

\footnotetext{
${ }^{1}$ Palestra ministrada na Aula Inaugural do Curso de Filosofia em março de 2018.

${ }^{2}$ Doutor em Filosofia pela UFPB/UFRN/UFPE, Mestre em Filosofia pela UFPB e Licenciado em Filosofia pela UFSM. Professor do Colegiado de Filosofia da UNIOESTE. E-mail: piresdasilveira@yahoo.com
} 
razoável precisão, qual seja, não sermos capazes de distinguir entre objeto e sujeito de investigação.

Definir o que somos é um objetivo que a Filosofia busca desde o seu princípio. Mas a busca em nos definirmos como tais não é uma tarefa que somente a Filosofia se propôs a fazer. Praticamente todas as esferas envolvidas pelo existir do homem procuram responder, a seu modo, a pergunta pelo que somos. Essa seria uma das razões que faz com que a tarefa de nos definirmos envolva um elevado grau de dificuldade na sua realização, já que ele está envolvido num paradoxo.

Ao mesmo tempo em que proliferam tentativas para definir o que somos, também aumentam, na exata proporção, as dificuldades em levarmos a bom termo tal propósito. Por ser um objeto que desperta o interesse de investigação em muitas áreas de interesse, poderíamos pensar que essa realidade representaria a obtenção de melhores condições para se alcançar a definição do homem, que haveria menos dificuldades dada a grande soma de esforços. No entanto, o que se percebe é um terreno onde existem muitas concepções e poucos acordos.

Ernst Cassirer, na obra An essay on man. An introduction to a philosophy of human culture (1944), afirma que o autoconhecimento constitui a principal tarefa da Filosofia. A condição que deve ser cumprida com vistas ao conhecimento do mundo seria o conhecimento aprofundado do ente que se dispõe a tal objetivo. Uma prova da preponderância do autoconhecimento sobre todos os demais objetivos da filosofia seria o ceticismo que, na opinião de Cassirer, não passaria de uma estratégia empregada com o fim de direcionar toda a investigação para o próprio homem.

Parece ser geralmente admitido que o autoconhecimento é o principal objetivo da investigação filosófica. Em todos os conflitos entre as diferentes escolas filosóficas esse objetivo permaneceu invariável e permanente: provou ser o ponto arquimédico, o centro fixo e imóvel, de todo o pensamento. Nem os mais céticos pensadores negaram a possibilidade e necessidade do autoconhecimento. Eles destruíram todos os princípios gerais concernentes à natureza das coisas, no entanto, tal destruição significa somente a abertura de um novo e mais seguro modo de investigação. Na história da filosofia, o ceticismo é frequentemente considerado como a contrapartida de um humanismo bem estabelecido. Com a negação e destruição da certeza objetiva do mundo externo, o cético espera que todos os pensamentos do homem se voltem para o seu próprio ser. O autoconhecimento dizem eles - é o primeiro pré-requisito da autorrealização (CASSIRER, 1944, p. 15, tradução e negrito nossos).

Se é possível estabelecer um acordo mínimo em torno da tese de que a busca pelo autoconhecimento pode ser considerada o principal objetivo da filosofia, o mesmo não ocorre quanto ao modo como devemos proceder na realização da mesma. Ao longo da história da filosofia essa busca foi orientada de muitas e 
diversas maneiras. Suas variâncias vão desde a necessidade de conhecimento do mundo externo para daí se depreender a posição do homem numa hierarquia cósmica, até a desconsideração total desta por meio de uma concentração absoluta em nós mesmos, como nos mostrou Ernst Cassirer quando se referiu ao ceticismo.

Max Scheler (1874-1928), em A situação do homem no cosmos (2008), afirma que a cultura europeia produziu três ideias incompatíveis de homem, ideias essas que tiveram origens e compreensões distintas deste, o que serve como evidencia a favor da afirmação de que o propósito de definir o homem não é uma tarefa fácil.

Se a um europeu culto se perguntar que entende ele pela palavra 'homem', quase sempre começam, na sua cabeça, a defrontar-se três âmbitos de ideias de todo inconciliáveis. Primeiro, o universo intelectual da tradição judia cristã de Adão e Eva, da criação, do paraíso e da queda. Em segundo lugar, o círculo de ideias da Grécia antiga em que, pela primeira vez no mundo, a autoconsciência do homem se elevou a um conceito da sua situação particular, mediante a tese de que o homem é homem pela posse da "razão", logos, phronesis, ratio, mens, etc. - Logos significa aqui tanto o discurso como a aptidão para apreender a 'quididade' de todas as coisas. Estreitamente unida a esta ideia está a doutrina segundo a qual existe também, subjacente ao todo integral, uma "razão" sobrehumana, da qual o homem, e só ele entre todos os seres, participa. O terceiro círculo intelectual, também ele já há muito transformado em tradição, é o da ciência moderna da natureza e da psicologia genética: o homem seria o resultado final, muito tardio, da evolução do planeta Terra - um ser que se distingue das formas animais que o precederam só pelo grau de complicação das combinações de energias e de capacidades que, em si, se encontram já na natureza infra-humana. Estes três círculos de ideias não têm entre si unidade alguma. Possuímos assim uma antropologia científico-natural, uma antropologia filosófica e uma antropologia teológica, que mutuamente se ignoram - do homem, porém, não possuímos nenhuma ideia unitária (SCHELER, 2008, p. 15).

Segundo ele, o que distinguiria o homem dos demais seres vivos não diria respeito ao estágio de evolução biológica desse em relação aos demais seres vivos, mas pelo fato do homem ser portador de uma espiritualidade, um ímpeto original que se apresenta como abertura para a compreensão do mundo.

Para Scheler, a tarefa de definir o homem se apresenta mais como um desafio à própria capacidade humana de obter conhecimento sobre si mesmo e o mundo, do que como um projeto de investigação com um objetivo possível de ser alcançado. Por ser uma área de interesse de vários campos de conhecimento, o que esperaríamos seria um cenário altamente favorável para o seu desenvolvimento, porém não é isso o que vemos, pelo contrário, “[...] por valiosa que possa ser a multiplicidade sempre crescente das ciências especiais que tratam do homem, ela, em vez de elucidar, oculta a sua essência” (SCHELER, 2008, p. 15). 
Pode parecer que eu esteja pretendendo o mesmo, que o que falei até aqui foi mais um esforço de escapar da resposta à pergunta pelo que sou ou me tornei. Meu objetivo, ao contrário, é mostrar que o que o sujeito que sou, se tornou e foi tornado, sofre uma profunda influência da Filosofia. Não consigo mais ver o mundo e a mim mesmo sem problematizar, sem apreender a mim e ao mundo como algo que espera por uma resposta mais satisfatória a respeito daquilo que sou e somos.

\section{Referências}

CASSIRER, Ernst. An essay on man. An introduction to a philosophy of human culture. New York: Double Anchor Books, 1944.

SCHELER, Max. A situação do homem no cosmos. Trad. Artur Morão. Lisboa, Martins Fontes: 2008.

Submissão: 04. 04. 2018 / Aceite: 30. 04. 2018. 